\title{
Climatic changes over the Arabian Peninsula and their correlation with Indian rainfall
}

\author{
Gargi Akhoury ${ }^{1, *}$ @ and Kirti AvisheK ${ }^{2}$ \\ ${ }^{1}$ Department of Physics, Birla Institute of Technology, Mesra, Ranchi 835 215, India. \\ ${ }^{2}$ Department of Civil and Environmental Engineering, Birla Institute of Technology, Mesra, Ranchi 835 215, India. \\ *Corresponding author.e-mail: gargiakhoury@bitmesra.ac.in
}

MS received 25 June 2018; revised 5 February 2019; accepted 14 February 2019; published online 4 June 2019

The summer monsoon rainfall affects most of the population of the Indian subcontinent. A slight variation of strength and spatial distribution in monsoon rains has huge societal impacts. So understanding the significance of its variability and the factors that control this variability is an imperative task. The Indian monsoon (also regarded as a global phenomenon) varies with the global climatic components like geopotential height, sea surface temperature, outgoing long-wave radiation and mean sea level pressure. The paper presents a statistical analysis of rainfall (over India) and climatic components (over the Arabian Peninsula) and the relationship between them. The period (1979-2013) shows a decrease in monsoon rainfall over the country. During this period, there was an increase in the tropospheric temperature over the Arabian Peninsula. Rainfall showed a direct relationship with the tropospheric temperature and thickness that gets stronger during the period (1979-2013). Except for the northeastern region of India, the rest showed a strong positive correlation with the middle and upper tropospheric temperature over the Arabian Peninsula while the lower tropospheric temperature showed a weak relationship. However, this correlation gets weakened during the El Nino and La Nina years. The findings will be helpful to enhance the Indian rainfall variation and the climatic factors responsible for this variation.

Keywords. Arabian peninsula; rainfall; geopotential height; temperature.

\section{Introduction}

In recent years, the irregular and unpredictable nature of the monsoon has triggered extensive financial loss and loss of life and property, along with the destruction of the environment and farmlands. Therefore, it has become a priority to understand and predict monsoon rainfall patterns. The Indian monsoon is a global phenomenon and various climatic components like geopotential height $(\mathrm{GpH})$, sea surface temperature (SST), outgoing long-wave radiation (OLR) and mean sea level pressure (MSLP) are responsible for its variation. Even the solar dimming effect is one of the essential reasons behind the variation (especially the weakening in rainfall) of rainfall over the country as suggested by Ramanathan et al. (2005). Aerosols cause a reduction in surface solar radiation showing a maximum over northern India and the Indian Ocean, thereby inducing a decrease in the northsouth surface temperature gradients and leading to a weakening in the monsoon rainfall (especially the southern part). As a continuation of this, Solomon et al. (2015) suggested that the increasing trend in 
Arabian dust emission affects the summer monsoon rainfall, especially over the southern part of India. Dust's radiative force can determine a positive dynamic reaction, which favours the establishment of low-pressure conditions on the Arabian Sea and, as a result, Arabian dust emissions and rainfall increase in southern India.

There have been studies examining the interannual variation in Indian rainfall and showing significant associations with regional and global climate variables. Notably, the months from June to September (known as the Indian summer monsoon rainfall, ISMR) are characterised by strong intraseasonal rainfall variability (Sikka 1980; Krishnamurthy and Shukla 2000) in the form of epochs of above- or below-normal rainfall activity, which further contribute to the interannual variability of all-India seasonal rainfall. The interannual variability of ISMR was deliberated on the large-scale features by Yadav 2009 for the period 1949-2005. The study concluded that the relationship between ISMR and the northwest of the North Atlantic SST has increased. It was also observed that during the excess years of ISMR, the SST is above average. According to Kripalani et al. (1999), there are domains over the Northern Hemisphere where the variations of the GpHs during the preceding months of the monsoon period are related to the interannual behaviour of the Indian monsoon rainfall (for 1958-1990). A significant adverse relationship was observed between the temperatures over the Tibetan Plateau $\left(25-45^{\circ} \mathrm{N}\right.$ and $\left.75-105^{\circ} \mathrm{E}\right)$ and the ISMR for the period 1957-1989 (cf. Bansod et al. 2003).

El Niño Southern Oscillation (ENSO) greatly influences the South Asian monsoon, henceforth regarded as one of the vital factors for the variation in Indian monsoon rainfall. It helps in modifying land-sea temperature contrast by inducing a tropospheric temperature gradient (that weakens in the warm phase and strengthens in the cold phase; Goswami 1998; Goswami and Xavier 2005) and through a modification of the Walker circulation. Accordingly, the warm phase of ENSO is responsible for a decrease and cold phase for an increase in the rainfall (Rasmusson and Carpenter 1983; Webster and Yang 1992; Ju and Slingo 1995).

Significant interdecadal changes in ENSO and the Indian monsoon have gone through invariance and coherency over the last $125 \mathrm{yr}$ (Torrence and Webster 1998; with the application of wavelet coherency to ENSO and the Indian monsoon indexes). The El Nino events with the warmest SST anomalies in the central Pacific are more effective in focusing on drought producing subsidence over India than events with the warmest SST anomalies in the eastern equatorial Pacific (Rajeevan and Pai 2007).

Because of the above climatic parameters and ENSO events, the Arabian Peninsula (AP) (region as taken by Almazroui et al. 2012) was opted for the study of variation in the Indian rainfall and also because AP is an essential component of the global atmospheric circulation. Due to the mid-latitude zone of baroclinic waves, the Middle East region is pushed northwards, during summer, under the influence of the Indian summer monsoon (ISM). There is an effect of ISM on the atmospheric circulation over the AP on the interannual timescale, and ISM is an essential driver of the summer circulation over the Middle East (Attada et al. 2017).

The variations in the ISM are linked to the variations of different variables like temperature, sea level pressure and wind velocity of other regions over the globe (Saha et al. 2017). Although many studies have been done for rainfall variation for a country (India) as a whole, there is limited literature exploring subdivisional rainfall. Therefore, the present study focuses on the climatic changes over the AP and its relationship with Indian rainfall for the period 1949-2013 (as very few studies cover the correlation between climatic changes over AP and the Indian rainfall).

\section{Materials and methods}

The Indian rainfall data were taken from Parthasarathy et al. (1995) and the updated data from the IITM website: http://www.tropmet.res. in/.

With reference to figure 1, the term 'homogeneous monsoon region' is coined by The India Meteorological Department (IMD). According to Parthasarathy et al. (1995), the five homogeneous regions over the country are based on the following criteria: (i) contiguity of area, (ii) contribution of monsoon seasonal rainfall to the annual amount, (iii) intercorrelations of subdivisional and all-India monsoon rainfall and (iv) relationship between subdivisional monsoon rainfall and regional/global circulation parameters.

The monthly GpH, MSLP, OLR and tropospheric temperature data were obtained from NOAA NCEP-NCAR CDAS-1 and NOAA NCEP 
Homogeneous Monsoon Regions

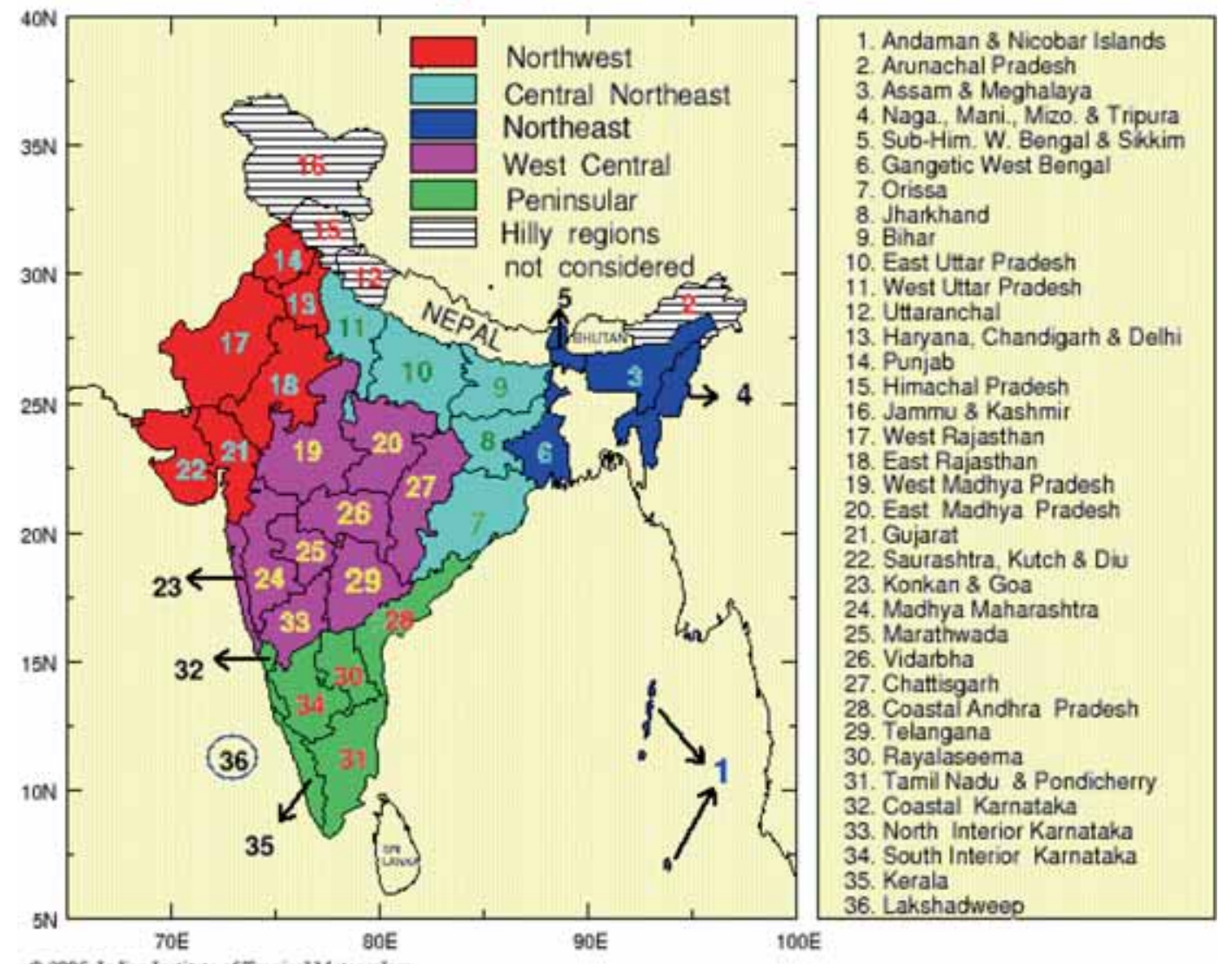

๑ 2005 , Indian Institute of Tropical Mteticocobgy

Figure 1. Homogeneous monsoon regions (source: Modified from Indian Institute of Tropical Meteorology).

CPC GLOBAL for OLR data. The packed description of data can be obtained from the site below (Kalnay et al. 1996): http://iridl.ldeo. columbia.edu/SOURCES/.NOAA/.NCEPNCAR/ .dataset_documentation.html.

The data period 1949-2016 and the months from June to September have been used in the analysis. The tropospheric thickness (TT) was measured by taking the difference between 250 and $1000 \mathrm{hPa}$ GpHs. The levels for the tropospheric temperature were taken as: the lower tropospheric temperature (LTT) (average of temperatures at 1000, 925, 850 and $700 \mathrm{hPa}$ ); the middle tropospheric temperature (MTT) (average of temperatures at 600 and $500 \mathrm{hPa}$ ); the upper tropospheric temperature (UTT) (average of temperatures at 400, 300 and $250 \mathrm{hPa}$ ); the whole tropospheric temperature (WTT) (average of temperatures from 1000 to $250 \mathrm{hPa}$ ). The subdivisional rainfall regions of India are taken as the all India rainfall (AIR), the northwest India rainfall (NWIR), the West Central India rainfall (WCIR), the central northeast
India rainfall (CNEIR), the northeast India rainfall (NEIR) and the Peninsular India rainfall (PIR) (figure 1).

\section{Results and discussion}

\subsection{Climatological fluctuations and descriptive analysis of rainfall}

Most of the population in the subcontinent (India) gets affected by the summer monsoon rainfall. Slight changes in its spatial distribution and strength have enormous societal impacts. So understanding its variability and what controls its variability is very important. For this, firstly the descriptive statistics of the monthly rainfall of subdivisions along with the Indian subcontinent from June to September are illustrated in tables 1-6. Instead of analysing India as a whole, it is better to analyse it on the subdivisional basis, as there may be some regions of deficient rains during the best monsoon 
Table 1. Descriptive statistics of monthly rainfall of AIR (1949-2016).

\begin{tabular}{lccccccccc}
\hline Rf $(\mathrm{mm})$ & Mean & SD & Skewness & Kurtosis & Min & Max & Range & CV & P-annual \\
\hline Jun & 158.1 & 31.9 & 0.1 & -0.4 & 89.9 & 228.5 & 138.6 & 20 & 14.65 \\
Jul & 269.2 & 36.1 & -1 & 3.1 & 121.3 & 341.5 & 220.2 & 13 & 24.95 \\
Aug & 244.9 & 31.5 & -0.1 & -0.7 & 185.5 & 307.5 & 122 & 13 & 22.7 \\
Sep & 169.4 & 35.4 & 0.4 & -0.8 & 113.5 & 250.7 & 137.2 & 21 & 15.7 \\
\hline
\end{tabular}

Table 2. Descriptive statistics of monthly rainfall of NWIR (1949-2016).

\begin{tabular}{lccccccccc}
\hline Rf $(\mathrm{mm})$ & Mean & SD & Skewness & Kurtosis & Min & Max & Range & CV & P-annual \\
\hline Jun & 63.3 & 33.4 & 0.4 & -0.5 & 4.3 & 146.9 & 142.6 & 53 & 11.32 \\
Jul & 188.4 & 64.7 & 0.1 & 0.5 & 22 & 345.7 & 323.7 & 34 & 33.73 \\
Aug & 164.4 & 60.5 & 0.3 & -0.7 & 40.1 & 308.3 & 268.2 & 37 & 29.42 \\
Sep & 85.4 & 58.5 & 0.6 & -0.5 & 5.7 & 235.6 & 229.9 & 69 & 15.28 \\
\hline
\end{tabular}

Table 3. Descriptive statistics of monthly rainfall of WCIR (1949-2016).

\begin{tabular}{lccccccccc}
\hline Rf $(\mathrm{mm})$ & Mean & SD & Skewness & Kurtosis & Min & Max & Range & CV & P-annual \\
\hline Jun & 161.2 & 47.3 & 0.4 & -0.6 & 73.7 & 269.3 & 195.6 & 29 & 15.12 \\
Jul & 299.2 & 59.8 & -0.2 & 1.4 & 89.2 & 432.4 & 343.2 & 20 & 28.06 \\
Aug & 276.9 & 50.7 & 0.2 & -0.5 & 178.8 & 380.6 & 201.8 & 18 & 25.98 \\
Sep & 181.6 & 59.3 & 0.5 & -0.3 & 70.5 & 324 & 253.5 & 33 & 17.03 \\
\hline
\end{tabular}

Table 4. Descriptive statistics of monthly rainfall of NEIR (1949-2016).

\begin{tabular}{lccccccccc}
\hline Rf $(\mathrm{mm})$ & Mean & SD & Skewness & Kurtosis & Min & Max & Range & CV & P-annual \\
\hline Jun & 367.6 & 65.9 & 0.4 & 0.6 & 233.4 & 574.1 & 340.7 & 18 & 18.22 \\
Jul & 401.8 & 74.8 & 0.6 & 0.3 & 287.5 & 646.3 & 358.8 & 19 & 19.92 \\
Aug & 338.8 & 54.3 & 0.3 & 0 & 239.7 & 509.9 & 270.2 & 16 & 16.79 \\
Sep & 272.6 & 58.1 & 0.3 & -0.6 & 166.2 & 393.6 & 227.4 & 21 & 13.51 \\
\hline
\end{tabular}

Table 5. Descriptive statistics of monthly rainfall of CNEIR (1949-2016).

\begin{tabular}{lccccccccc}
\hline Rf $(\mathrm{mm})$ & Mean & SD & Skewness & Kurtosis & Min & Max & Range & CV & P-annual \\
\hline Jun & 155.3 & 58.3 & 0.6 & 0 & 64.9 & 319.5 & 254.6 & 38 & 13.34 \\
Jul & 304.8 & 53.1 & -0.3 & 0.2 & 148.6 & 413 & 264.4 & 17 & 26.17 \\
Aug & 299.7 & 49.4 & 0 & 0.4 & 151.1 & 416.9 & 265.8 & 16 & 25.73 \\
Sep & 208.4 & 45.8 & -0.4 & 0 & 94 & 303.1 & 209.1 & 22 & 17.89 \\
\hline
\end{tabular}

Table 6. Descriptive statistics of monthly rainfall of PIR (1949-2016).

\begin{tabular}{lccccccccc}
\hline Rf $(\mathrm{mm})$ & Mean & SD & Skewness & Kurtosis & Min & Max & Range & CV & P-annual \\
\hline Jun & 163.9 & 36.8 & 0.8 & 1.1 & 90.3 & 283.9 & 193.6 & 22 & 13.95 \\
Jul & 193.4 & 43.3 & -0.1 & 0.2 & 84.5 & 294.1 & 209.6 & 22 & 16.47 \\
Aug & 163.1 & 39.8 & 0 & -0.4 & 81.5 & 252.7 & 171.2 & 24 & 13.89 \\
Sep & 150.7 & 44.9 & 0.2 & -0.5 & 51.4 & 252 & 200.6 & 30 & 12.83 \\
\hline
\end{tabular}

years and vice versa (Parthasarathy et al. 1993). This regional monsoon rainfall variability leads to important consequences leading to the fact that subdivisional analysis yields better formulae for forecasting.
Concerning tables 1-6, the rainfall variability of an area can be smoothly and strongly indicated by the variation $\mathrm{CV}$ (coefficient of variation) values. For any standard distribution data, the skewness is zero and for any symmetric data, it is near zero. 
(a) JJAS 500hPa Temperature Anomaly: 1949-2013

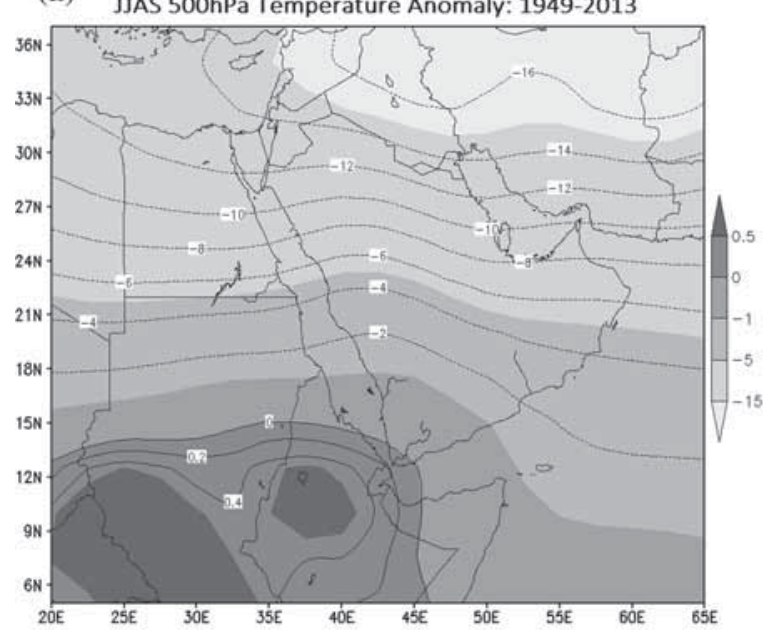

(b)

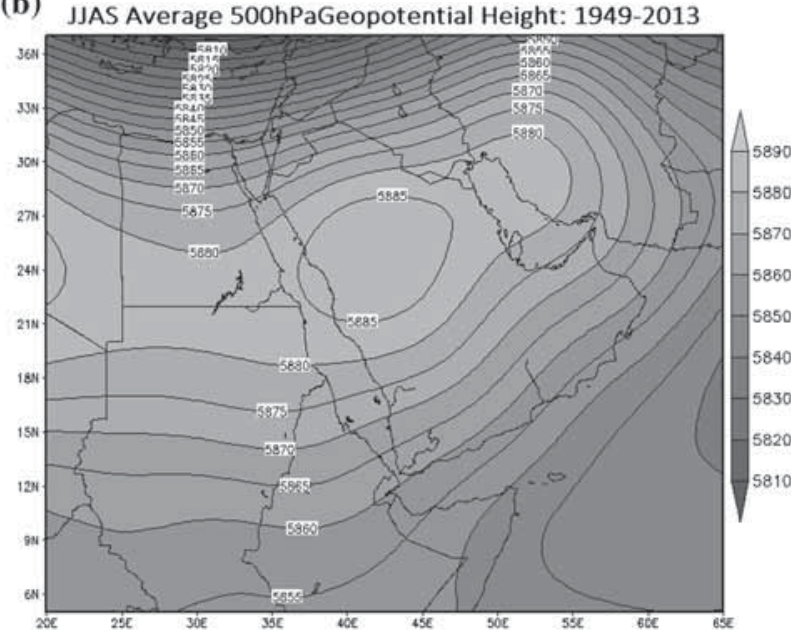

(c) JJAS Mean Sea Level Pressure: 1949-2013

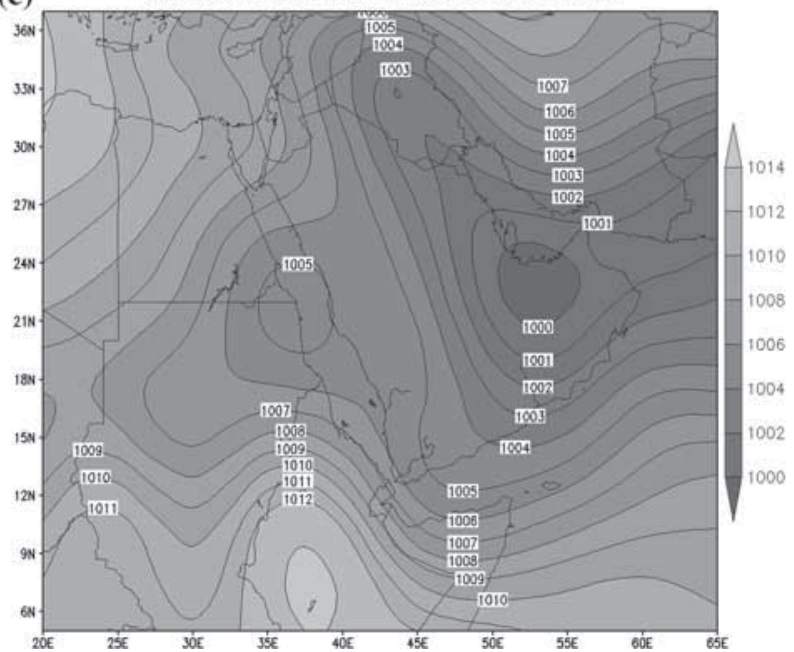

Figure 2. $(\mathbf{a}-\mathbf{c})$ Climatology of temperature, GpH and MSLP of AP.

Also, the negative values indicate that data are skewed to the left and positive values indicate to the right, while for kurtosis, peak distribution is indicated by the positive values and flat distribution is indicated by the negative values. The percentage of the annual ( $\mathrm{P}$-annual) rainfall is also shown in the tables.

Figure 2(a-c) represents the climatology of temperature, $\mathrm{GpH}$ at $500 \mathrm{hPa}$ level and MSLP for the season June-July-August-September. The temperature varies from $-13^{\circ} \mathrm{C}$ to $-2^{\circ} \mathrm{C}$ over the $\mathrm{AP}$ region. The $\mathrm{GpH}$ is valuable to detect troughs and ridges, which are the upper level equivalent to surface cyclones and anticyclones (climatology shows the middle-level $\mathrm{GpH}$ at $500 \mathrm{hPa}$ ). Table 7 shows the climatological and fluctuation features for the parameters LTT, MTT, UTT, WTT, TT, MSLP and OLR (1979-2013) of the AP for the period 1949-2013.
3.2 Comparison of two subperiods 1949-1978 and 1979-2013

The climate change during the period (1979-2013) was observed by taking the difference between the two subperiods, i.e., (1979-2013)-(1949-1978). As for the globe as a whole, surface air temperatures over land have risen at about double the ocean rate after 1979 (Parthasarathy et al. 1993; Hartmann et al. 2013). The Student's $t$-test tested the data at $1 \%$ (indicated by ' 1 ') and $5 \%$ (indicated by ' 5 ') level of significance. As per the Intergovernmental Panel on Climate Change (IPCC) report, after the availability of satellites since 1979 , surface temperature trends for 1979-2000 were higher. Thus, according to Parthasarathy et al. (1993) and Hartmann et al. (2013), 1979 can be marked as an important year for the climatic changes, by which the above two subperiods were considered. 
Table 7. Climatological and fluctuation features of AP.

\begin{tabular}{lcccr}
\hline & June & July & August & \multicolumn{1}{c}{ September } \\
\hline \multicolumn{1}{l}{ Tropospheric temperature } & & & \\
LTT & $24.10 \pm 0.52$ & $24.22 \pm 0.53$ & $23.83 \pm 0.52$ & $22.33 \pm 0.55$ \\
MTT & $-2.05 \pm 0.38$ & $-1.10 \pm 0.43$ & $-1.27 \pm 0.41$ & $-2.36 \pm 0.43$ \\
UTT & $-28.80 \pm 0.68$ & $-27.15 \pm 0.48$ & $-27.61 \pm 0.45$ & $-29.44 \pm 0.66$ \\
WTT & $0.66 \pm 0.42$ & $1.47 \pm 0.36$ & $1.11 \pm 0.37$ & $-0.42 \pm 0.42$ \\
Other climatological parameters & & & \\
TT & $10,892.00 \pm 17.44$ & $10,936.67 \pm 14.84$ & $10,924.08 \pm 15.40$ & $10,861.74 \pm 18.50$ \\
MSLP & $1006.67 \pm 0.75$ & $1005.59 \pm 0.89$ & $1006.46 \pm 0.91$ & $1009.06 \pm 1.00$ \\
OLR & $281.32 \pm 3.87$ & $276.77 \pm 4.47$ & $276.64 \pm 4.05$ & $279.95 \pm 4.31$ \\
\hline
\end{tabular}

Table 8. Recent 35-yr changes in parameters of AP as compared to the period 1949-1978.

\begin{tabular}{lcccc}
\hline & June & July & August & September \\
\hline \multicolumn{4}{l}{ Tropospheric temperature } \\
LTT & $0.81^{1}$ & $0.80^{1}$ & $0.80^{1}$ & $0.83^{1}$ \\
MTT & $0.35^{1}$ & $0.27^{1}$ & $0.32^{1}$ & 0.18 \\
UTT & 0.22 & -0.10 & -0.03 & 0.01 \\
WTT & $0.51^{1}$ & $0.38^{1}$ & $0.42^{1}$ & $0.41^{1}$ \\
Other climatological & parameters & \\
TT & $16.87^{1}$ & $10.33^{1}$ & $12.66^{1}$ & $12.16^{1}$ \\
MSLP & $0.86^{1}$ & $1.11^{1}$ & $1.15^{1}$ & $1.08^{1}$ \\
\hline
\end{tabular}

Table 8 displays the recent 35 yr (1979-2013) changes in climatic parameters of the AP in comparison to the period 1949-1978. It is clear from the table that LTT, MTT and WTT increase for the period 1979-2013 over the region. There is also an increase in $\mathrm{TT}$ for the recent $35 \mathrm{yr}$ (where $\mathrm{TT}$ is a function of the average virtual temperature between 1000 and $250 \mathrm{hPa}$; thickness will increase if the average virtual temperature increases and vice versa; source: https://www.weather.gov/source/zhu/ZHU_Traini ng_Page/Miscellaneous/Heights_Thicknesses/thick ness_temperature.htm).
It was examined that, the all-over India along with its subdivisions, experience a low rainfall in the monsoon months for the period 1979-2013. Table 9 shows the difference between the two subperiods, i.e., (1979-2013)-(1949-1978) along with Sen's slope values (a decreasing trend was observed).

\subsection{Correlation of subdivisional rainfall with climatic parameters of the $A P$}

Table 10 shows the relationship between the rainfall (of defined regions) and the climatic components (of the AP) for the whole period, i.e., from 1949 to 2013. A weak correlation is observed between the subdivisional rainfall regions and the LTT (from June to September). The MTT showed an excellent positive correlation with all the rainfall regions except NEIR and PIR during September. A strong positive correlation was observed with the upper and the WTT during the months June, July and September except for the region NEIR. The rainfall regions, except for NEIR, showed an excellent positive correlation with the TT during the months June and September, whereas MSLP is strongly and negatively

Table 9. Recent 35-yr changes in rainfall as compared to the period 1949-1978.

\begin{tabular}{|c|c|c|c|c|c|c|c|c|}
\hline & \multicolumn{8}{|c|}{ Rainfall } \\
\hline & \multicolumn{2}{|c|}{ June } & \multicolumn{2}{|c|}{ July } & \multicolumn{2}{|c|}{ August } & \multicolumn{2}{|c|}{ September } \\
\hline & $\begin{array}{c}(1949-1978)- \\
(1979-2013)\end{array}$ & Sen's slope & $\begin{array}{r}(1949-1978)- \\
(1979-2013)\end{array}$ & Sen's slope & $\begin{array}{c}(1949-1978)- \\
(1979-2013)\end{array}$ & Sen's slope & $\begin{array}{c}(1949-1978)- \\
(1979-2013)\end{array}$ & Sen's slope \\
\hline AIR & 88 & 2.96 & -155 & -3.61 & -82 & -1.17 & -104 & -2.47 \\
\hline NWIR & 109 & 4.66 & -126 & -2.06 & -45 & 2.56 & -214 & 0.22 \\
\hline WCIR & 141 & 4.56 & -247 & -3.92 & -64 & -0.88 & -196 & -5.75 \\
\hline NEIR & -470 & -8.69 & 48 & -1.23 & -158 & -5.59 & 158 & 1.39 \\
\hline CNEIR & 221 & 3.95 & -55 & -1.14 & -241 & -6.64 & -64 & -3.01 \\
\hline PIR & 111 & 1.20 & -245 & -5.79 & 79 & 2.32 & 45 & 1.20 \\
\hline
\end{tabular}


Table 10. Correlation of subdivisional rainfall with climatic components of the APfor the period 19792013.

\begin{tabular}{|c|c|c|c|c|}
\hline Regions & June & July & August & September \\
\hline \multicolumn{5}{|c|}{ LTT (1949-2013) } \\
\hline AIR & 0.13 & -0.25 & -0.08 & -0.12 \\
\hline NWIR & 0.20 & -0.23 & 0.00 & -0.13 \\
\hline WCIR & 0.15 & -0.20 & -0.04 & -0.13 \\
\hline NEIR & -0.25 & 0.00 & -0.03 & 0.05 \\
\hline CNEIR & 0.09 & -0.01 & -0.22 & -0.02 \\
\hline PIR & 0.14 & -0.29 & 0.11 & -0.02 \\
\hline \multicolumn{5}{|c|}{ MTT (1949-2013) } \\
\hline AIR & 0.43 & 0.30 & 0.28 & 0.52 \\
\hline NWIR & 0.19 & 0.20 & 0.16 & 0.30 \\
\hline WCIR & 0.38 & 0.32 & 0.25 & 0.46 \\
\hline NEIR & -0.03 & -0.20 & -0.10 & 0.17 \\
\hline CNEIR & 0.42 & 0.23 & 0.11 & 0.39 \\
\hline PIR & 0.24 & 0.13 & 0.29 & 0.18 \\
\hline \multicolumn{5}{|c|}{ UTT (1949-2013) } \\
\hline AIR & 0.63 & 0.32 & 0.32 & 0.65 \\
\hline NWIR & 0.32 & 0.28 & 0.21 & 0.52 \\
\hline WCIR & 0.55 & 0.34 & 0.23 & 0.55 \\
\hline NEIR & 0.13 & -0.38 & 0.00 & 0.16 \\
\hline CNEIR & 0.55 & 0.17 & 0.18 & 0.37 \\
\hline PIR & 0.27 & 0.25 & 0.25 & 0.18 \\
\hline \multicolumn{5}{|c|}{ WTT (1949-2013) } \\
\hline AIR & 0.50 & 0.06 & 0.15 & 0.38 \\
\hline NWIR & 0.32 & 0.03 & 0.12 & 0.26 \\
\hline WCIR & 0.46 & 0.10 & 0.13 & 0.31 \\
\hline NEIR & -0.07 & -0.22 & -0.04 & 0.15 \\
\hline CNEIR & 0.44 & 0.13 & -0.04 & 0.27 \\
\hline PIR & 0.27 & -0.04 & 0.24 & 0.12 \\
\hline \multicolumn{5}{|c|}{ TT (1949-2013) } \\
\hline AIR & 0.57 & 0.21 & 0.23 & 0.51 \\
\hline NWIR & 0.32 & 0.15 & 0.17 & 0.37 \\
\hline WCIR & 0.51 & 0.24 & 0.18 & 0.42 \\
\hline NEIR & 0.00 & -0.28 & -0.04 & 0.17 \\
\hline CNEIR & 0.51 & 0.18 & 0.03 & 0.32 \\
\hline PIR & 0.28 & 0.09 & 0.27 & 0.16 \\
\hline \multicolumn{5}{|c|}{ MSLP (1949-2013) } \\
\hline AIR & -0.22 & -0.40 & -0.30 & -0.60 \\
\hline NWIR & -0.01 & -0.30 & -0.13 & -0.52 \\
\hline WCIR & -0.17 & -0.43 & -0.16 & -0.55 \\
\hline NEIR & -0.33 & 0.25 & -0.18 & -0.02 \\
\hline CNEIR & -0.18 & -0.08 & -0.29 & -0.27 \\
\hline PIR & 0.00 & -0.41 & -0.20 & -0.18 \\
\hline \multicolumn{5}{|c|}{ Correlation with OLR (1979-2013) } \\
\hline AIR & -0.19 & -0.15 & -0.25 & -0.28 \\
\hline NWIR & 0.00 & -0.02 & -0.05 & -0.23 \\
\hline WCIR & -0.07 & -0.13 & -0.16 & -0.23 \\
\hline NEIR & -0.45 & -0.01 & -0.16 & 0.13 \\
\hline CNEIR & -0.18 & -0.25 & -0.15 & -0.30 \\
\hline PIR & 0.02 & 0.03 & -0.35 & -0.09 \\
\hline
\end{tabular}

*Bold numbers indicate a good correlation. correlated with most of the rainfall regions during July and September.

The two subperiods (1949-1978 and 1979-2013) were compared by correlation approach. Figure 3 $(\mathrm{a}-\mathrm{c})$ represents the correlation coefficients of AIR and its subdivisional rainfall with the WTT, TT and the MSLP. AIR shows a good direct relationship of tropospheric temperature and rainfall for the months June and September for both the subperiods.

The region NWIR shows a negative correlation in July for 1949-1978, but becomes a strong positive correlation in 1979-2013. The region WCIR shows an excellent positive correlation except during August (1979-2013). There is a weak correlation for the rainfall region NEIR for both the subperiods. The region CNEIR shows an excellent direct correlation for the months June and September. The positive correlation increases for the region PIR during 1979-2013 in all the several months. The TT over the AP shows a strong direct correlation with the rainfall (regions NWIR, WCIR and CNEIR), especially for June and September. A monsoon expert at the Russian Academy of Sciences, Elena Surovyatkina, 2018 (as referred in Saudi Gazette [18]) explained the fact that the overheating of the landmass has led to the intensification of monsoon rainfall in central and southern India over the last decade. Koll (2018) (as referred in Saudi Gazette 2018) explained that there had been an increase in the fluctuation of monsoon winds due to rapid warming in the Arabian Sea and nearby places. This leads to intensification in the monsoon rainfall, which may be one of the reasons for an increasingly positive correlation during the period (1979-2013), especially in the subdivisions NWIR, WCIR, CNEIR and PIR.

According to Sir Gilbert Walker, ENSO is the chief component in the context of Indian rainfall. Generally, a positive phase of ENSO (negative Southern Oscillation Index and positive SST over central and east Pacific) favours below normal monsoon rainfall over India and vice versa during the negative phase of ENSO. The ENSO years were considered (cf. McPhaden 2003) for the period 1949-2013 to analyse rainfall relationship with other variables in an enhanced way. Figure 4 (a and d) shows the correlation coefficient during the El Nino and La Nina years. It was found that during the El Nino and La Nina years a weak correlation was observed for all India rainfall with 

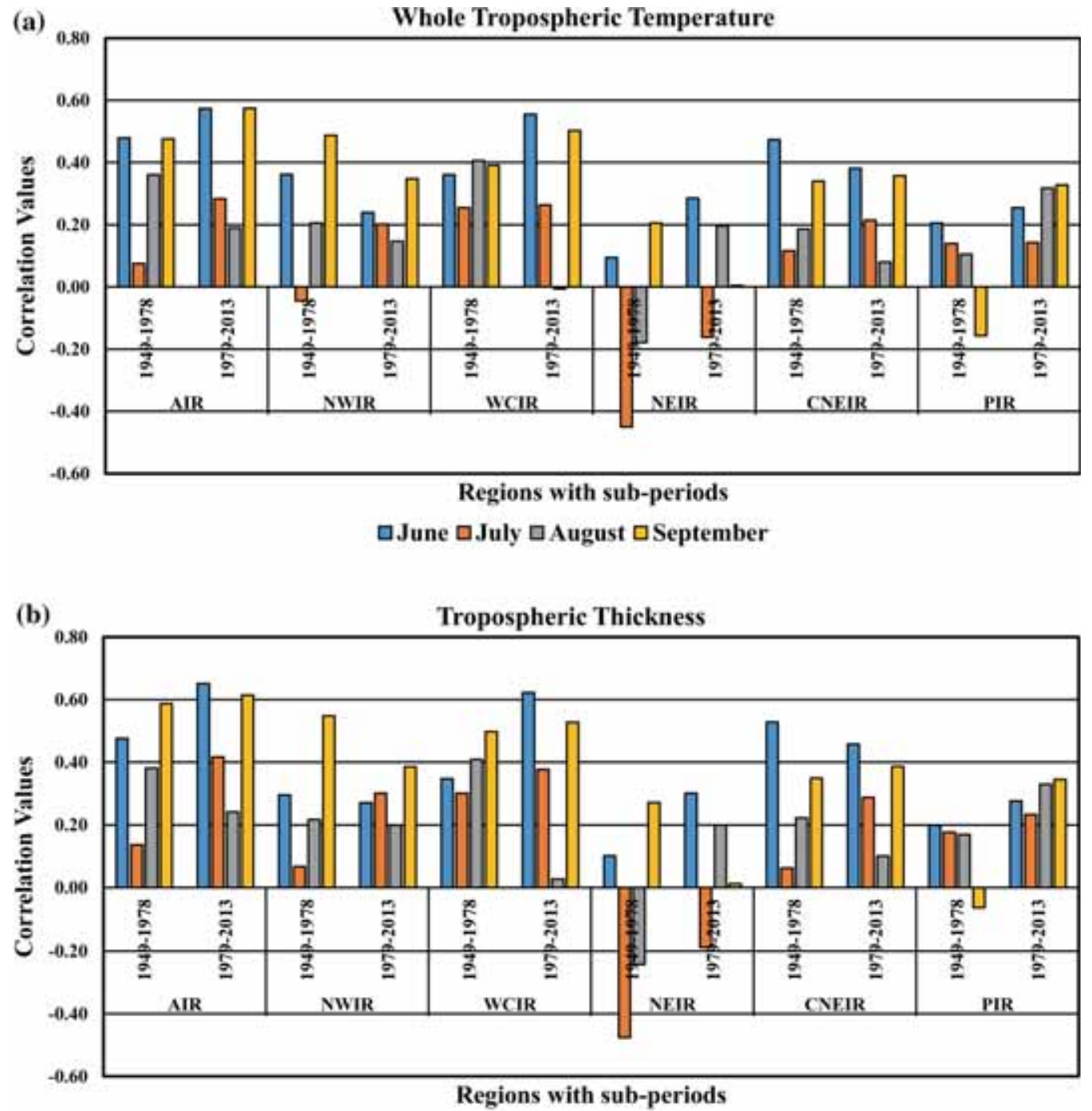

$\square$ June $\square$ July $\square$ August $\square$ September

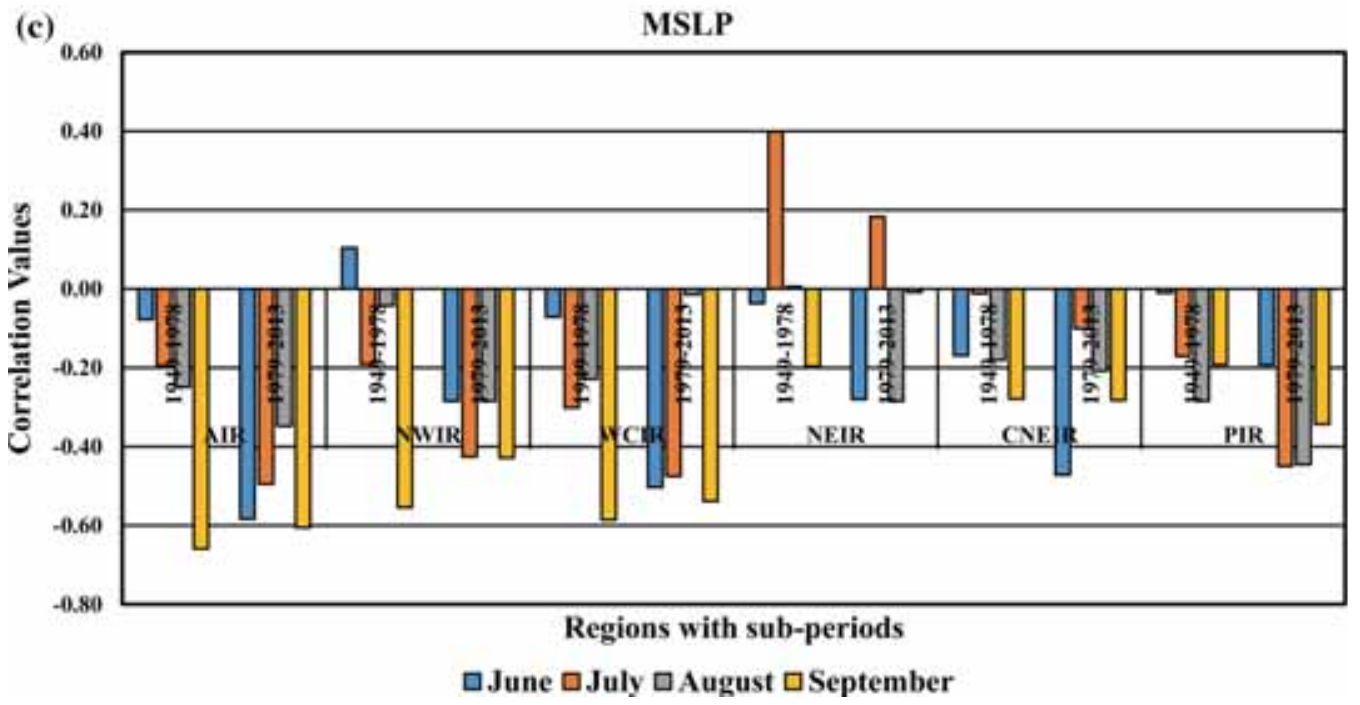

Figure 3. (a-c) Correlation comparison for two subperiods of subdivisional rainfall and different parameters. 
(a)

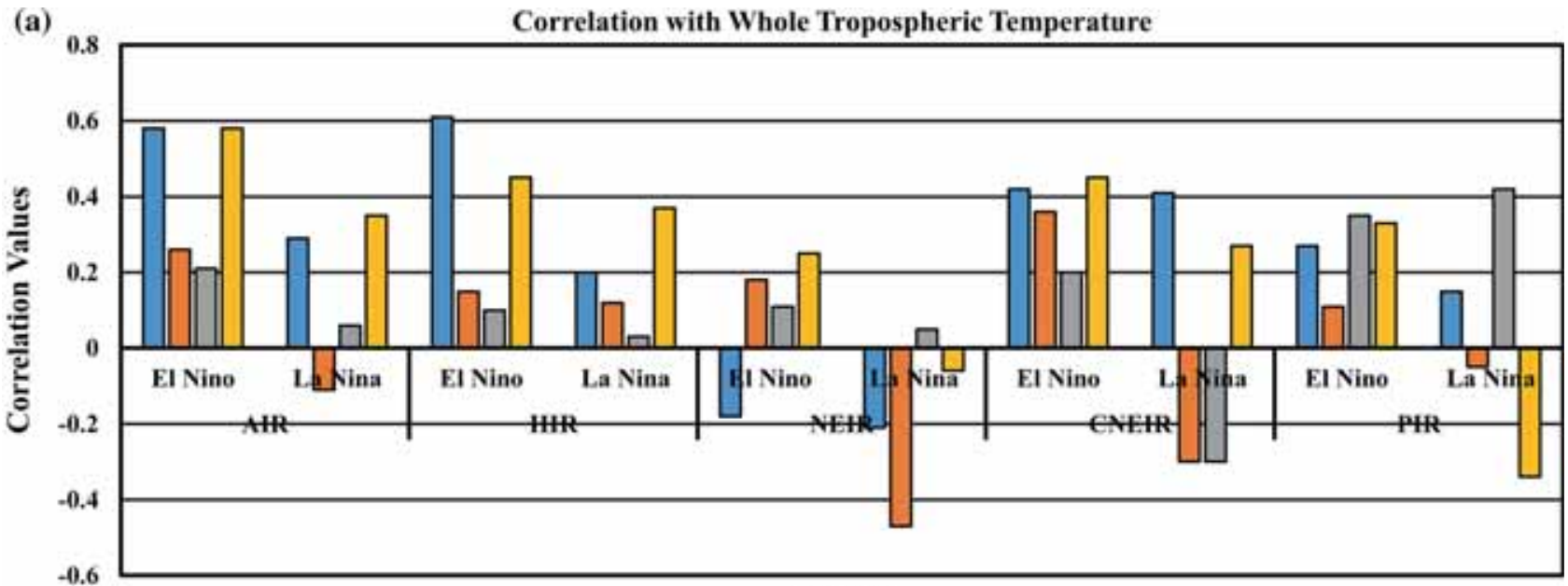

Regions

$\square$ June $\square$ July $\square$ August $\square$ September

(b)

Correlation with Tropospheric Thickness

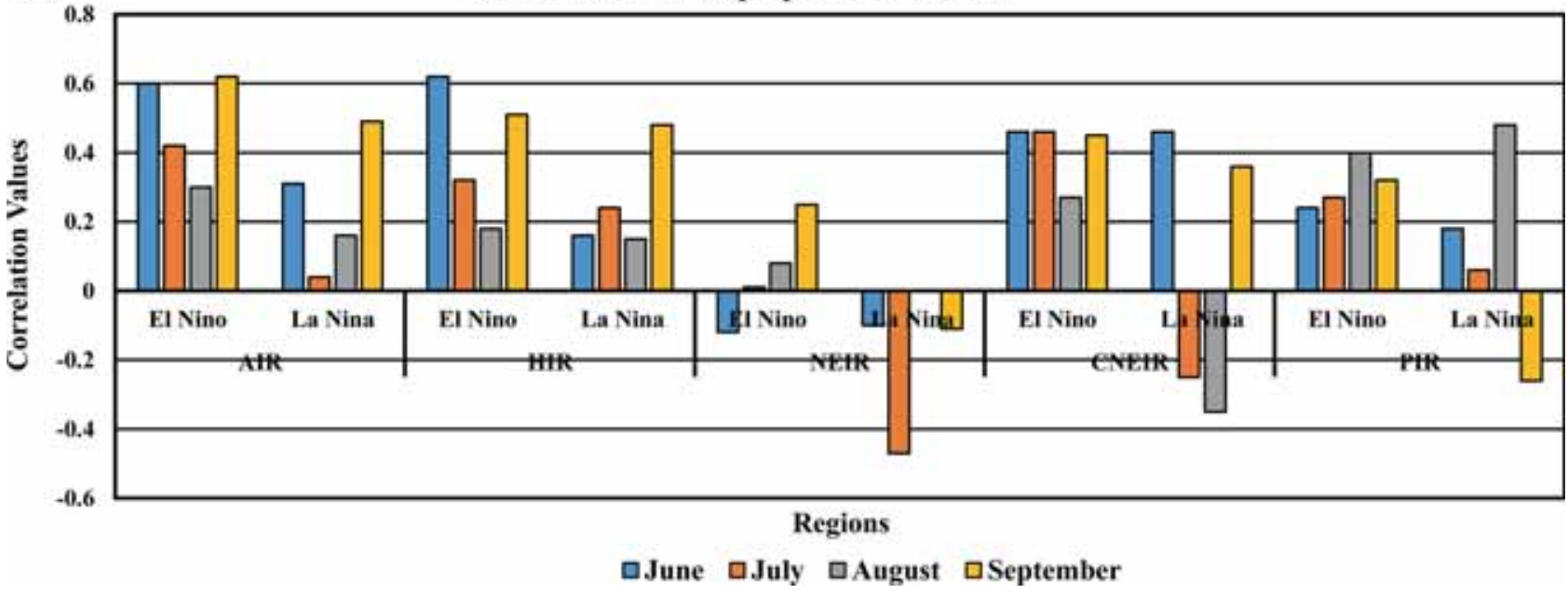

Figure 4. (a and $\mathbf{b}$ ) Correlation coefficient during El Nino and La Nina.

tropospheric temperature and thickness except for the months June and September (the subdivisions NWIR and WCIR were combined as homogeneous India rainfall region). Table 9 shows the correlation of rainfall with OLR (of the AP) for the period 1979-2013. There is a weak negative correlation between subdivisional rainfall with OLR except for the regions NEIR and CNEIR which show an excellent negative correlation during the months June and September, respectively.

\section{Conclusion}

The months of June to September are considered very important as there is excessive rainfall during this period, which is also essential from the agriculture point of view. The country
(India) receives approximately $80 \%$ of rainfall during these months. In recent years, i.e., 19792013, the Indian rainfall experienced a low rainfall during monsoon months (from June to September). The AP showed an increase in the lower, middle and WTT during the period 1979-2013 as compared to the period 1949-1978. The TT also showed an increment for 1979-2013 (where TT is a function of the average virtual temperature between 1000 and $250 \mathrm{hPa}$; thickness will increase if the average virtual temperature increases and vice versa).

The regions AIR, NWIR, WCIR and CNEIR showed a direct relationship with the tropospheric temperature and thickness for June and September which gets stronger in the later period (1979-2013). While the regions NEIR and PIR showed a weak correlation with the tropospheric temperature and 
thickness of AP, a strong negative correlation was observed between MSLP of AP and the subdivisional rainfall of all the months for the period 1979-2013. This correlation gets weakened during the El Nino and La Nina years, except for June and September. A weak negative correlation was seen of subdivisional rainfall with OLR of the AP. Thus, with the help of the above results, we can say that climatic changes in the AP may affect Indian rainfall (or there may be a relationship between Indian rainfall and the climatic components of AP), especially during June to September, which are the highest rainfall months. The result seems to be perfect in the context of Indian rainfall. It can be more accurate if other parameters (such as wind, solar radiation and non-atmospheric parameters such as SST or ice cover) and regions (such as regions of centres of action like Azores high, Siberian high) are added to the analysis and compared with Indian rainfall variability.

\section{Acknowledgements}

We thank the IRI Data Library, which is an authoritative and freely accessible online data repository and helps the user to view, download and analyse the reanalysis climate data. We are very thankful to the Indian Meteorological Department for providing us with the Rainfall data. We thank Dr Ashwini Ranade for her support and guidance. A big thank to Dr Gnanseelan for his motivation. We would also like to thank the Department of Physics and the Department of Civil and Environmental and Engineering, Birla Institute of Technology, Mesra, Ranchi for their cooperation.

\section{References}

Almazroui M, Nazrul Islam M, Athar H, Jonesa P D and Ashfaqur Rahman M 2012 Recent climate change in the Arabian Peninsula: Annual rainfall and temperature analysis of Saudi Arabia for 1978-2009; Int. J. Climatol. 32 953-966, https://doi.org/10.1002/joc.3446.

Attada R, Dasari H P, Omar K and Hoteit I 2017 Indian summer monsoon influence on the Arabian Peninsula summer climate; Geophys. Res. Abstr. 19 EGU2017-19293.

Bansod S D, Yin Z-Y, Lin Z B and Zhang K 2003 Thermal field over Tibetan plateau and Indian summer monsoon rainfall; Int. J. Climatol. 23 1589-1605.

Goswami B N 1998 Interannual variations of Indian summer monsoon in a GCM: External conditions versus internal feedbacks; J. Clim. 11 501-521.
Goswami B N and Xavier P K 2005 ENSO control on the south Asian monsoon through the length of the rainy season; Geophys. Res. Lett. 32 L18717, https://doi.org/10. 1029/2005GL023216.

Hartmann D L, Klein Tank A M G, Rusticucci M, Alexander L V, Brönnimann S, Charabi Y, Dentener F J, Dlugokencky E J, Easterling D R, Kaplan A, Soden B J, Thorne P W, Wild M and Zhai P M 2013 Observations: Atmosphere and surface; In: Climate change 2013: The physical science basis. Contribution of working group I to the fifth assessment report of the intergovernmental panel on climate change (eds) Stocker T F, Qin D, Plattner G-K, Tignor M, Allen S K, Boschung J, Nauels A, Xia Y, Bex $\mathrm{V}$ and Midgley P M, Cambridge University Press, Cambridge, UK and New York, NY, USA.

Ju J and Slingo J M 1995 The asian summer monsoon and ENSO; Quart. J. Roy. Meteorol. Soc. 121 1133-1168.

Kalnay E, Kanamitsu M, Kistler R, Collins W, Deaven D, Gandin L, Iredell M, Saha S, White G, Woollen J, Zhu Y, Leetmaa A, Reynolds R, Chelliah M, Ebisuzaki W, Higgins W, Janowiak J, Mo K C, Ropelewski C, Wang J, Jenne R and Joseph D 1996 The NCEP/NCAR 40-year reanalysis project; Bull. Am. Meteorol. Soc. 77 437-471.

Kripalani R H, Kulkarni A, Inamdar S R and Prasad K D 1999 Teleconnections: Northern hemisphere lower stratospheric geopotential heights and Indian monsoon rainfall; Meteorol. Atmos. Phys. 69 195-203, https://doi.org/10. $1007 /$ BF01030421.

Krishnamurthy V and Shukla J 2000 Intraseasonal and interannual variability of rainfall over India; J. Climate. 13 4366-4377, https://doi.org/10.1175/1520-0442(2000)013, 0001:IAIVOR.2.0.CO;2.

McPhaden M J 2003 El Nino and La Nina: Causes and global consequences, The earth system: Physical and chemical dimensions of global environmental change; In: Encyclopedia of Global Environmental Change, vol. 1, pp. 353-370.

Parthasarathy B, Munot A A and Kothawale D R 1995 Monthly and seasonal rainfall series for all-India homogeneous regions and meteorological subdivisions: 1871-1994, IITM Research Report-065. Indian Institute of Tropical Meteorology, Pune, India.

Parthasarathy B, Rupa Kumar K and Munot A A 1993 Homogeneous Indian monsoon rainfall: Variability and prediction; Proc. Indian Acad. Sci (Earth Planet. Sci.) 102(1), 121-155.

Rajeevan M and Pai D S 2007 On the El nino-Indian monsoon predictive relationships; Geophys. Res. Lett. 34 L04704, https://doi.org/10.1029/2006GL028916.

Ramanathan V, Chung C, Kim D, Bettge T, Buja L, Kiehl J, Washington W M, Fu Q, Sikka D R and Wild M 2005 Atmospheric brown clouds: Impacts on South Asian climate and hydrological cycle; Proc. Natl. Acad. Sci. USA 102 5326-5333.

Rasmusson E M and Carpenter T H 1983 The relationship between the eastern Pacific sea surface temperature and rainfall over India and Sri Lanka: Mon. Weather Rev. 111 $517-528$.

Saha M, Mitra P and Nanjundiah R S 2017 Deep learning for predicting the monsoon over the homogeneous regions of India; J. Earth Syst. Sci. 126, https://doi.org/10.1007/ s12040-017-0838-7. 
Saudi Gazette 2018 India's devastating rains match climate change forecasts (website link: http://saudi gazette.com.sa/article/541874/World/Asia/Indias-devast ating-rains-match-climate-change-forecasts).

Sikka D R (1980) Some aspects of the large-scale fluctuations of summer monsoon rainfall over India in relation to fluctuations in the planetary and regional scale circulation parameters; Proc. Indian Acad. Sci. (Earth Planet. Sci.) 89 179-195

Solmon F, Nair V S and Mallet M 2015 Increasing Arabian dust activity and the Indian summer monsoon; Atmos. Chem. Phys. Discus. 15 4879-4907, https://doi.org/10. 5194/acpd-15-4879-2015.

Corresponding editor: A K SAHAI
Torrence C and Webster P J 1998 Interdecadal changes in the ENSO-monsoon system; J. Climate 12.

Trenberth K E 2011 Changes in precipitation with climate change; Clim. Res. Publ. 2011, https://doi.org/10.3354/ cr00953.

Webster P J and Yang S 1992 Monsoon and ENSO: Selectively interactive systems; Q. J. R. Meteorol. Soc. 118 877-926.

Yadav R K 2009 Changes in the large-scale features associated with the Indian summer monsoon in recent decades; Int. J. Climatol. 29 117-133, https://doi.org/10.1002/joc. 1698. 